\title{
OriginaL
}

\section{Induction of thyroid remission using rituximab in a patient with type 3 autoimmune polyglandular syndrome including Graves' disease and type 1 diabetes mellitus: A case report}

\author{
Akira Kurozumi, Yosuke Okada, Tadashi Arao, Manabu Narisawa, Keiichi Torimoto, Sunao Yamamoto and \\ Yoshiya Tanaka
}

First Department of Internal Medicine, School of Medicine, University of Occupational and Environmental Health, Japan

\begin{abstract}
Rituximab (RTX) is a monoclonal antibody that targets the B-cell-specific CD20 antigen. Recent reports indicate that RTX is effective against type 1 diabetes mellitus (T1DM) and hematologic as well as autoimmune diseases. Other studies have indicated that RTX therapy leads to the remission of recurrent or active Graves' disease (GD). However, the efficacy of RTX in Japanese patients with autoimmune polyglandular syndrome (APS) has not been reported to date. Herein, we report the case of a patient with GD and T1DM with sustained endogenous insulin secretion capacity. To protect pancreatic $\beta$ cells, we administered RTX at a dose of $500 \mathrm{mg}$ (approximately $300 \mathrm{mg} / \mathrm{m}^{2}$ ) on 2 occasions 1 week apart. After treatment, no adverse effects were observed, and thyroid stimulating hormone receptor antibody (TRAb) was no longer detectable 4 months after RTX administration. In addition, the reduction in TRAb level improved thyroid function. Notably, the treatment induced remission over a period of 1 year after the diagnosis of GD.
\end{abstract}

Key words: Rituximab, Graves' disease, Type 1 diabetes mellitus, Autoimmune polyglandular syndrome

RITUXIMAB (RTX) is an anti-CD20 monoclonal antibody that depletes B cells [1]. It has been reported to be useful for the treatment of autoimmune and hematologic diseases [2,3], and various other diseases, including type 1 diabetes mellitus (T1DM) [4].

Although Graves' disease (GD) is an autoimmune disease, to date, no immunosuppressive agents have been adopted for clinical use in patients with GD. The current goal of GD therapy is to normalize and maintain thyroid function by drug therapy with thiamazole (MMI), which suppresses the production of thyroid hormones and/or other molecules, with an aim to restore normal immunoregulatory mechanisms. However, treatment with anti-thyroid drugs is associated with high incidence of serious side effects, such as agranulocytosis (MMI: $0.35 \%$, propylthiouracil

Submitted Apr. 4, 2014; Accepted Sep. 17, 2014 as EJ14-0152 Released online in J-STAGE as advance publication Oct. 1, 2014

Correspondence to: Yoshiya Tanaka, M.D., Ph.D., First Department of Internal Medicine, School of Medicine, University of Occupational and Environmental Health, Japan, 1-1 Iseigaoka, Yahatanishi-ku, Kitakyushu 807-8555, Japan.

E-mail: tanaka@med.uoeh-u.ac.jp

(c) The Japan Endocrine Society
(PTU): $0.37 \%$ [5]) and liver dysfunction (MMI $30 \mathrm{mg} /$ day: $6.9 \%$, MMI $15 \mathrm{mg}$ /day: $6.6 \%$, PTU $300 \mathrm{mg}$ /day: $26.9 \%$ [6]), and the rate of complete remission has been less than satisfactory (approximately $40-50 \%$ in Europe [7-10], approximately $40-60 \%$ in Japan [1113 ], and approximately $50 \%$ in USA [14]).

In the context of treatment of thyroid diseases, RTX has been reported to be useful for the treatment of thyroid-associated ophthalmopathy (TAO) [15-17]. In the study of Salvi et al. [15], a significantly greater improvement in Clinical Activity Score, representing an index of proper management of patients with TAO, was observed in patients with TAO complicated by hyperthyroidism after 30 weeks of RTX treatment than after steroid therapy. Relapse of active TAO did not occur in any of the patients treated with RTX, but occurred in $10 \%$ of patients who underwent steroid therapy.

Recently, the efficacy of immunosuppressive therapy with RTX for GD has been investigated. RTX therapy leads to the remission of recurrent or active GD and effectively maintains the remission [18-20]. However, to date, there is little or no information on the efficacy and safety of RTX in Japanese patients with 
autoimmune polyglandular syndrome (APS), including autoimmune thyroid disease. Herein, we report the successful use of RTX in a patient with GD associated with T1DM, and in whom remission was maintained.

\section{Clinical Trial Registry}

This trial, RTX treatment for T1DM, was registered with the University Hospital Medical Information Network (UMIN) (No. UMIN000013622).

\section{Case Report}

In July 2012, a 40-year-old man presented with hyperhidrosis, tremors, and insomnia, but no palpitation. Two months later, the subject experienced thirstiness, polydipsia, polyuria, and a weight loss of $10 \mathrm{~kg}$ over the 2-month period. He was diagnosed with thyrotoxicosis [thyroid-stimulating hormone $(\mathrm{TSH})<0.05$ $\mu \mathrm{IU} / \mathrm{mL}$, free thyroxine (FT4) $4.14 \mathrm{ng} / \mathrm{dL}]$ and DM [hemoglobin A1c (HbA1c) 8.5\%, plasma glucose over $200 \mathrm{mg} / \mathrm{dL}$, and referred to our hospital for further examination. The thyroid function test results indicated thyrotoxicosis. The thyroid stimulating hormone receptor antibody (TRAb) titer was $12.5 \mathrm{U} / \mathrm{mL}$, and the thyroid ultrasound examination indicated an enlarged thyroid gland and increased blood flow. On the other hand, thyroid stimulating antibody (TSAb) was negative and there were no symptoms of TAO. On the basis of these findings, the patient was diagnosed with GD and diabetes with poor glycemic control (HbAlc level, 9.8\%; postprandial plasma glucose level, $227 \mathrm{mg} / \mathrm{dL}$ ). Urine analysis indicated the presence of ketone bodies, although arterial blood gas analysis indicated no evidence of ketoacidosis (blood pH, 7.378).

The patient was admitted to our department, and treatment for GD with $30 \mathrm{mg}$ of MMI and $50 \mathrm{mg}$ of potassium iodide (KI) was initiated. With regards to the stage of diabetes, the patient was negative for glutamic acid decarboxylase (GAD) antibody (Table 1). In addition, the increased blood glucose levels might have been exacerbated by the oxyhyperglycemia associated with GD. However, owing to the absence of a family history of diabetes and high plasma glucose level at fasting, an islet antigen (IA)-2 antibody test was performed. The patient was positive for IA-2 antibody, with an initial titer of $1.7 \mathrm{U} / \mathrm{mL}$, and was therefore diagnosed with T1DM. After excluding Addison's dis-

Table 1 Laboratory data on the first admission

\begin{tabular}{|c|c|c|c|c|c|}
\hline $\mathrm{CBC}$ & & ABG & & DM-related & \\
\hline WBC $\left(/ \mathrm{mm}^{3}\right)$ & 4700 & $\mathrm{pH}$ & 7.378 & FPG (mg/dL) & 297 \\
\hline Neutrophils (\%) & 53.9 & $\mathrm{PCO}_{2}$ (Torr) & 44.1 & PPG (mg/dL) & 500 \\
\hline Eosinophils (\%) & 3.2 & $\mathrm{HCO}_{3}^{-}(\mathrm{mEq} / \mathrm{mL})$ & 25.4 & HbAlc (\%) & 9.8 \\
\hline Basophils (\%) & 0.2 & Biochemistry & & GA $(\%)$ & 33.6 \\
\hline Lymphocytes (\%) & 34.4 & Total protein $(\mathrm{g} / \mathrm{dL})$ & 7.3 & $\mathrm{u}-\mathrm{CPR}(\mu \mathrm{g} /$ day $)$ & 34.2 \\
\hline Monocytes (\%) & 8.3 & Albumin $(\mathrm{g} / \mathrm{dL})$ & 4.4 & u-Alb (mg/g Cre) & 2.3 \\
\hline $\mathrm{RBC}\left(\times 10^{4} / \mathrm{mm}^{3}\right)$ & 498 & AST (IU/L) & 17 & $\mathrm{GAD}-\mathrm{Ab}(\mathrm{U} / \mathrm{mL})(0.0-1.50)^{\text {ฯ }}$ & $<1.3$ \\
\hline $\mathrm{Hb}(\mathrm{g} / \mathrm{dL})$ & 13.9 & $\operatorname{ALT}(\mathrm{IU} / \mathrm{L})$ & 23 & $\mathrm{IA}-2 \mathrm{Ab}(\mathrm{U} / \mathrm{mL})(0.0-0.4)^{\uparrow}$ & 1.7 \\
\hline Hct $(\%)$ & 39.9 & $\gamma$-GTP (IU/L) & 16 & Thyroid-related & \\
\hline Platelet count $\left(\times 10^{4} / \mathrm{mm}^{3}\right)$ & 18.0 & LDL-C (mg/dL) & 38 & $\mathrm{TSH}(\mu \mathrm{IU} / \mathrm{mL})$ & $<0.01$ \\
\hline Urine & & $\mathrm{TG}(\mathrm{mg} / \mathrm{dL})$ & 155 & FT3 (pg/mL) & 16.23 \\
\hline $\mathrm{pH}$ & 7.38 & HDL-C (mg/dL) & 31 & FT4 (ng/dL) & $>7.77$ \\
\hline glucose & $(4+)$ & BUN (mg/dL) & 23 & $\operatorname{TRAb}(\mathrm{U} / \mathrm{mL})(<2.0)^{\Uparrow}$ & 12.5 \\
\hline protein & $(-)$ & Cre (mg/dL) & 0.56 & $\mathrm{TG}-\mathrm{Ab}(\mathrm{U} / \mathrm{mL})(<28.0)^{\natural}$ & 47 \\
\hline ketone & $(1+)$ & eGFR (mL/min) & 126.9 & $\mathrm{TPO}-\mathrm{Ab}(\mathrm{U} / \mathrm{mL})(<16.0)^{\natural}$ & 50 \\
\hline \multirow[t]{6}{*}{ O.B. } & $(-)$ & $\mathrm{Na}(\mathrm{mEq} / \mathrm{mL})$ & 131 & HLA typing & \\
\hline & & $\mathrm{K}(\mathrm{mEq} / \mathrm{mL})$ & 4.4 & DQB1*04:02:01 & \\
\hline & & $\mathrm{Cl}(\mathrm{mEq} / \mathrm{mL})$ & 95 & DQB1*06:04:01 & \\
\hline & & & & DQA1*03:03/01:02 & \\
\hline & & & & DQA1*03:03/01:08 & \\
\hline & & & & DQA $1 * 03: 03 / 01: 09$ & \\
\hline
\end{tabular}

ॠnormal range 
ease, and owing to characteristic features such as hair loss and vitiligo, the patient was diagnosed simultaneously with type 3 APS associated with GD and T1DM, which exhibited acute-onset pattern. In the Japanese population, common human leukocyte antigen haplotypes have been reported for T1DM and autoimmune thyroid diseases [21]. As shown in Table 1, the patient had the DQA1*03:03 haplotype, which is commonly associated with GD, in addition to the DQA $1 * 01$ and DQA1*03 haplotypes, which are present in patients with type 3 APS. For the treatment of T1DM, intensive insulin therapy was initiated, and a favorable glycemic control was achieved with a combination of bolus insulin (glulisine) at breakfast, lunch, dinner (5-3-2u) and basal insulin (glargine) at morning (1-0-0u). The patient was discharged from the hospital after achieving control of GD and T1DM.

The urinary C-peptide immunoreactivity was 34.2 $\mu \mathrm{g} /$ day, indicating that the capacity for endogenous insulin secretion was intact and that the patient was in the honeymoon phase. Accordingly, the patient was readmitted 1 month after the initial hospital discharge for the suppression of B-cell antibody production by the RTX-mediated depletion of B cells. The aim of RTX therapy was to induce immunosuppression and protect against pancreatic $\beta$ cell damage. The use of RTX was approved by the Ethics Review Committee of our university (No. 11-002) and all patients signed an informed consent form. Treatment with RTX at a dose of $500 \mathrm{mg}$ (approximately $300 \mathrm{mg} / \mathrm{m}^{2}$ ) on 2 occasions at a 1-week interval did not cause any side effects, including infusion reactions (e.g., fever, hypotension, and tachycardia) and infection. However, laboratory test results on readmission, including a serum aspartate aminotransferase (AST) level of $83 \mathrm{IU} / \mathrm{L}$, alanine aminotransferase (ALT) level of $114 \mathrm{IU} / \mathrm{L}$, and $\gamma$-glutamyl transpeptidase (GTP) level of $210 \mathrm{IU} / \mathrm{L}$, indicated liver dysfunction; hepatitis B surface antigen (HBs-Ag), hepatitis B core antigen (HBc-Ag) and hepatitis $\mathrm{C}$ virus antibody ( $\mathrm{HCV}-\mathrm{Ab})$ were negative. These changes were considered to represent adverse effects of MMI. Accordingly, MMI was discontinued, resulting in the immediate improvement in liver function. Subsequently, the patient was discharged from treatment and was prescribed $50 \mathrm{mg}$ of $\mathrm{KI}$ for the hyperthyroidism.

As shown in Fig. 1, the patient's glycemic levels were stable since hospital discharge. At present, $\mathrm{HbAlc}$ level is $6.9 \%$, and the daily insulin requirement is $6 \mathrm{U}$, indicating stable glycemic control. C-peptide immunoreactivity (CPR) Index (representing beta cell function) continued to be within the normal range after treatment (baseline: 1.82, after 6-month RTX treatment: 1.50) (Fig. 1). In addition, the IA-2 antibody (initial titer of $1.7 \mathrm{U} / \mathrm{mL}$ ) was no longer detectable 8 months after RTX administration. As shown in Fig. 2,

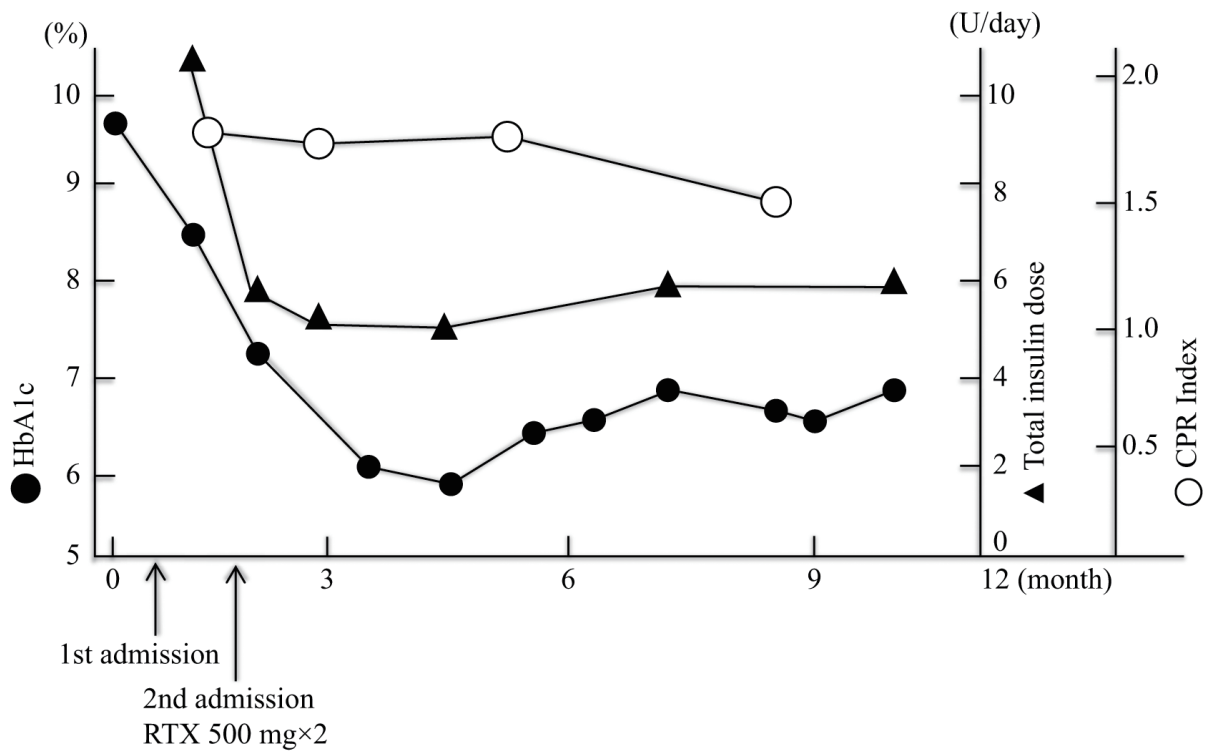

Fig. 1 Time course of diabetes data Serial changes in HbAlc level, daily insulin requirement and CPR Index during hospitalization and at follow-up. 


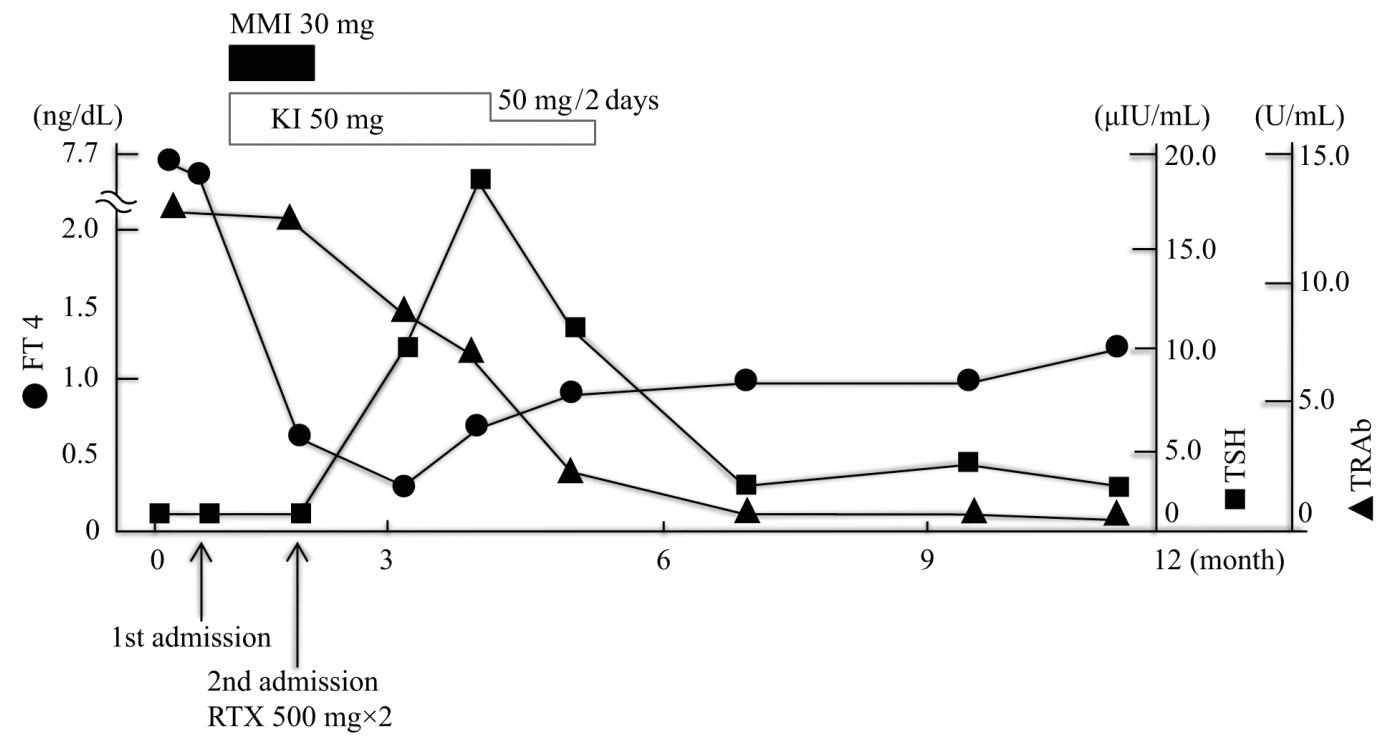

Fig. 2 Time course of thyroid data

Serial changes in thyroid function: FT4, TSH, and TRAb. MMI was discontinued due to liver dysfunction. After readmission, RTX was administered on two occasions one week apart. KI was discontinued following correction of hypothyroidism. Approximately one year after the diagnosis of GD, the disease remains in remission in the absence of any anti-thyroid drug therapy.

the TRAb level was $11.1 \mathrm{U} / \mathrm{mL}$ before RTX treatment, decreased to $6.8 \mathrm{U} / \mathrm{mL}$ and $2.1 \mathrm{U} / \mathrm{mL}$ at 1 and 3 months after treatment, respectively, and was no longer detectable at 4 months after RTX treatment. Furthermore, thyroid function gradually improved with the reduction of TRAb levels. Because hypothyroidism (TSH 18.65 $\mu \mathrm{IU} / \mathrm{mL}$, FT4 $0.68 \mathrm{ng} / \mathrm{dL}$ ) occurred 4 months after the onset of hyperthyroidism, the KI dosage was reduced to $50 \mathrm{mg}$ every alternate day. TSH and FT4 levels 5 months after onset were $11.91 \mu \mathrm{IU} / \mathrm{mL}$ and $0.78 \mathrm{ng} /$ $\mathrm{dL}$, respectively, and KI was discontinued. At present, approximately 1 year since the diagnosis of GD, the disease remains in remission in the absence of any anti-thyroid drug therapy (TSH, FT4, and TRAb levels: $3.91 \mu \mathrm{IU} / \mathrm{mL}, 1.05 \mathrm{ng} / \mathrm{dL}$, and $0.7 \mathrm{U} / \mathrm{mL}$, respectively).

\section{Discussion}

Herein, we described the case of a patient with type 3 APS associated with GD, who was treated with 500 $\mathrm{mg}$ of RTX (approximately $300 \mathrm{mg} / \mathrm{m}^{2}$ ) on 2 occasions 1 week apart. The treatment induced disease remission over a period of 1 year since the diagnosis of GD. The TRAb titers decreased from $11.1 \mathrm{IU} / \mathrm{L}$ to undetectable level 4 months after RTX treatment. In addition, serum TRAb level remained undetectable for 1 year, whereas serum immunoglobulin (Ig) G level did not change with RTX treatment. RTX was well tolerated with no infusion reaction and no serious infection. Heemstra et al. [18] used RTX for the treatment of 13 patients with relapsing GD, and reported that 9 patients remained in remission at a median follow-up of 18 months, whereas 4 patients were considered non-responders and subsequently treated with radioiodine. These authors found no differences in thyroid size between the 9 responders and the 4 non-responders. However, the baseline FT4 level was significantly higher in the non-responders. Because of the small number of patients, no significant differences were observed in TSH binding inhibitory immunoglobulin (TBII) levels between the responders and non-responders. However, many patients with low TBII levels remained in remission. Moreover, the mean TBII levels decreased significantly in the 9 responders, from a median level of $4 \mathrm{IU} / \mathrm{L}$ at baseline to $1.9 \mathrm{IU} / \mathrm{L}$ at 26 weeks.

El Fassi and colleagues [19] studied 20 GD patients, among which 10 were treated with RTX (RTX+), whereas 10 were left untreated (RTX-). Furthermore, these patients were treated with MMI for approximately 4 months. Four RTX+ patients remained in remission with a median follow-up of 705 days, whereas all RTXpatients had a relapse within 1 year. The RTX-/RTX+ 
Table 2 Serial changes in immunogloblin before administration of RTX and follow-up

\begin{tabular}{|c|c|c|c|}
\hline & Before administration of RTX & After 9 months & After 1 year \\
\hline $\operatorname{IgG}(\mathrm{mg} / \mathrm{dL})(778-1604)$ ฯ & 1286 & 1203 & 1265 \\
\hline $\operatorname{IgA}(\mathrm{mg} / \mathrm{dL})(117-413) \pi$ & 213 & 253 & 291 \\
\hline $\operatorname{IgM}(\mathrm{mg} / \mathrm{dL})(37-200)^{ף}$ & 108 & 63 & 76 \\
\hline
\end{tabular}

hazard ratio for relapse was 2.30. The mean decrease in TRAb levels was not significantly different between the 2 groups. However, the duration of euthyroidism was inversely correlated with TRAb levels in all patients. Moreover, all patients with baseline TRAb levels of $>5$ IU/L showed relapse despite the use of RTX, the 5 RTXpatients with baseline TRAb levels of $<5$ IU/L relapsed, whereas the $4 \mathrm{RTX}+$ patients with baseline TRAb levels of $<5$ IU/L remained in remission. The authors concluded that RTX treatment induced sustained remission in patients with low TRAb levels.

Salvi and coworkers [15] used RTX for the treatment of hyperthyroidism in patients with TAO. The mean change in serum TRAb levels after RTX treatment was not significantly different from that of patients treated with intravenous glucocorticoids (IVGC) for 30 weeks. El Fassi et al. [22] reported that RTX therapy, in addition to the standard MMI therapy, prolonged the period of remission with a median follow-up of 400 days. However, it did not induce a reduction in TRAb levels when compared with MMI monotherapy.

RTX exerts its effects primarily through the suppression of B-cell antibody production and depletion of B cells, as reviewed by Hasselbach [20] and Wang et al. [23]. In the patient under study, TRAb titers decreased from $11.1 \mathrm{IU} / \mathrm{L}$ before the use of RTX to undetectable levels 4 months after RTX treatment. At the last followup examination 1 year after RTX treatment, the serum remained negative for TRAb. However, as described above, the decrease in the TRAb level after RTX treatment was similar to that observed in the control group, when compared with steroid therapy or combination therapy with MMI. Therefore, it appears that other factors, such as the cytokine-producing capacity of B cells and their impact on $\mathrm{T}$ cells, may need to be considered. Elevated serum interleukin (IL)-18 levels have been reported in patients with GD [24, 25]. Because RTX was reported to markedly reduce serum IL-18 levels in patients with rheumatoid arthritis [26], the possible involvement of IL-18 cannot be ruled out. Moreover, it has been suggested that in multiple sclerosis [27] and
T1DM [4], RTX may suppress T cells through the suppression of the antigen-presenting function of $\mathrm{B}$ cells. In the patient under investigation, $\mathrm{T}$ cells were evaluated by lymphocyte analysis, and no apparent changes were observed during the first 6 months after RTX treatment. However, a longer follow-up period is necessary for a more accurate assessment.

El Fassi et al. [19] reported the side effects in 5 of 10 patients after an initial RTX infusion. Four days after the second infusion, 2 patients developed serum sickness (joint pain and fever), and during the 1-year follow-up period, 2 patients had mild infections. In other reports $[15,18], 50 \%$ of the patients developed infusion reactions and joint pain after the initial RTX infusion. However, these symptoms were alleviated with acetaminophen and glucocorticoids, and the side effects improved after the second infusion. The patient under study showed no infusion reactions, such as fever, hypotension, tachycardia, and pruritus, after the first or the second dose of RTX. Although serum IgM level decreased from $108 \mathrm{mg} / \mathrm{dL}$ (measured before RTX treatment) to $63 \mathrm{mg} / \mathrm{dL}$ measured at 9 months after the completion of treatment (Table 2), as reported in previous studies [22], these levels recovered. There were no marked changes in the serum levels of $\operatorname{IgG}$ and $\operatorname{IgA}$, and no infections were detected.

Furthermore, Pescovitz et al. [4] reported that RTX treatment was associated with preservation, at least in part, of beta-cell function over a period of 1 year in patients with newly diagnosed type $1 \mathrm{DM}$. For example, significantly lower levels of $\mathrm{HbAlc}$ and lower insulin dose were noted in patients of the RTX group. Similarly, our patient had stable low level of HbAlc, required less insulin after treatment, and RTX treatment effectively preserved beta-cell function (e.g., CPR Index continued to be within the normal range after treatment).

Herein, we described the case of a patient with type 3 APS associated with GD, in whom remission was maintained for 1 year after treatment with RTX. With regard to the treatment of GD patients, it has been 
reported that RTX is effective in patients with relatively low serum titers of TRAb. In particular, RTX may exhibit good efficacy in properly selected candidates, including those who cannot be treated with anti-thyroid drugs because of their adverse effects, those who do not desire either surgery or isotope therapy, those who cannot be treated with isotopes because of the TAO, and those for whom RTX is expected to be effective for the ophthalmopathy itself. In contrast to surgery or isotope therapy, RTX administration does not require replacement therapy after treatment. Although some issues need to be resolved, such as the assessment of safety and cost, the effectiveness of RTX for the treatment of GD can be demonstrated in the near future through randomized controlled trials. In the meantime, we will perform a thorough patient follow-up to assess thyroid function, potential adverse events, and overall health status.

\section{References}

1. Reff ME, Carner K, Chambers KS, Chinn PC, Leonard JE, et al. (1994) Depletion of B cells in vivo by a chimeric mouse human monoclonal antibody to CD20. Blood 83: 435-445.

2. Nielsen CH, El Fassi D, Hasselbalch HC, Bendtzen K, Hegedüs L (2007) B-cell depletion with rituximab in the treatment of autoimmune diseases. Graves' ophthalmopathy the latest addition to an expanding family. Expert Opin Biol Ther 7: 1061-1078.

3. Edwards JC, Cambridge G (2006) B-cell targeting in rheumatoid arthritis and other autoimmune diseases. Nat Rev Immunol 6: 394-403.

4. Pescovitz MD, Greenbaum CJ, Krause-Steinrauf H, Becker DJ, Gitelman SE, et al. (2009) Rituximab, B-lymphocyte depletion, and preservation of beta-cell function. N Engl J Med 361: 2143-2152.

5. Tajiri J, Noguchi S (2004) Antithyroid drug-induced agranulocytosis: Special reference to normal white blood cell count agranulocytosis. Thyroid 14: 459-462.

6. Nakamura H, Noh JY, Ttoh K, Fukata S, Miyauchi A, et al. (2007) Comparison of methimazole and propylthiouracil in patients with hyperthyroidism caused by Graves' disease. J Clin Endocrinol Metab 92: 21572162.

7. Allannic H, Fauchet R, Orgiazzi J, Madec AM, Genetet B, et al. (1990) Antithyroid drugs and Graves' disease: a prospective randomized evaluation of the efficacy of treatment duration. J Clin Endocrinol Metab 70: 675679.

8. García-Mayor RV, Páramo C, Luna Cano R, Pérez Mendez LF, Galofré JC, et al. (1992) Antithyroid drug and Graves' hyperthyroidism. Significance of treatment duration and TRAb determination on lasting remission. J Endocrinol Invest 15: 815-820.

9. Weetman AP, Pickerill AP, Watson P, Chatterjee VK, Edwards OM (1994) Treatment of Graves' disease with the block-replace regimen of antithyroid drugs: the effect of treatment duration and immunogenetic susceptibility on relapse. $Q J$ Med 87: 337-341.

10. Maugendre D, Gatel A, Campion L, Massart C, Guilhem I, et al. (1999) Antithyroid drugs and Graves' disease- -prospective randomized assessment of long-term treatment. Clin Endocrinol (Oxf) 50: 127-132.

11. Mashio Y, Beniko M, Matsuda A, Koizumi S, Matsuya K, et al. (1997) Treatment of hyperthyroidism with a small single daily dose of methimazole: a prospective long-term follow-up study. Endocr J 44: 553-558.

12. Takamatsu J, Kuma K, Mozai T (1986) Serum triiodothyronine to thyroxine ratio: a newly recognized predictor of the outcome of hyperthyroidism due to Graves' disease. J Clin Endocrinol Metab 62: 980-983.

13. Konishi T, Okamoto Y, Ueda M, Fukuda Y, Harusato I, et al. (2011) Drug discontinuation after treatment with minimum maintenance dose of an antithyroid drug in Graves' disease: a retrospective study on effects of treatment duration with minimum maintenance dose on lasting remission. Endocr J 58: 95-100.

14. Sundaresh V, Brito JP, Wang Z, Prokop LJ, Stan MN, et al. (2013) Comparative effectiveness of therapies for Graves' hyperthyroidism: a systematic review and network meta-analysis. J Clin Endocrinol Metab 98: 36713677.

15. Salvi M, Vannucchi G, Campi I, Currò N, Dazzi D, et al. (2007) Treatment of Graves' disease and associated ophthalmopathy with the anti-CD20 monoclonal antibody rituximab: an open study. Eur J Endocrinol 156: 33-40.

16. El Fassi D, Nielsen CH, Hasselbalch HC, Hegedüs L (2006) Treatment-resistant severe, active Graves' ophthalmopathy successfully treated with B lymphocyte depletion. Thyroid 16: 709-710.

17. Khanna D, Chong KK, Afifiyan NF, Hwang CJ, Lee DK, et al. (2010) Rituximab treatment of patients with severe, corticosteroid-resistant thyroid-associated ophthalmopathy. Ophthalmology 117: 133-139.

18. Heemstra KA, Toes RE, Sepers J, Pereira AM, Corssmit EP, et al. (2008) Rituximab in relapsing Graves' disease, a phase II study. Eur J Endocrinol 159: 609-615.

19. El Fassi D, Nielsen CH, Bonnema SJ, Hasselbalch HC, Hegedüs L (2007) B lymphocyte depletion with the monoclonal antibody rituximab in Graves' disease: a controlled pilot study. J Clin Endocrinol Metab 92: 
1769-1772.

20. Hasselbalch HC (2003) B-cell depletion with rituximab-a targeted therapy for Graves' disease and autoimmune thyroiditis. Immunol Lett 88: 85-86.

21. Hashimoto K, Maruyama H, Nishiyama M, Asaba K, Ikeda Y, et al. (2005) Susceptibility alleles and haplotypes of human leukocyte antigen DRB1, DQA1, and DQB1 in autoimmune polyglandular syndrome type III in Japanese population. Horm Res 64: 253-260.

22. El Fassi D, Banga JP, Gilbert JA, Padoa C, Hegedüs L, et al. (2009) Treatment of Graves' disease with rituximab specifically reduces the production of thyroid stimulating autoantibodies. Clin Immunol 130: 252258.

23. Wang SH, Baker JR Jr (2006) Targeting B cells in
Graves' disease. Endocrinology 147: 4559-4560.

24. Miyauchi S, Matsuura B, Onji M (2000) Increased levels of serum interleukin-18 in Graves' disease. Thyroid 10: 815-819.

25. Miyauchi S, Matsuura B, Ueda T, Eguchi T, Tamaru M, et al. (2013) Interleukin-18 induces insulin resistance in the hyperthyroid state. Endocr J 60: 449-455.

26. Keren Z, Braun-Moscovici Y, Markovits D, Rozin A, Nahir M, et al. (2009) Depletion of B lymphocytes in rheumatoid arthritis patients modifies IL-8-anti-IL-8 autoantibody network. Clin Immunol 133: 108-116.

27. Hauser SL, WaubantE, Arnold DL, Vollmer T, Antel J, et al. (2008) B-cell depletion with rituximab in relapsing-remitting multiple sclerosis. $N$ Engl J Med 358: 676-688. 